\title{
Efficient Synthesis of Structured Phospholipids Containing Short-Chain Fatty Acids over a Sulfonated Zn-SBA-15 Catalyst
}

Jianghua Zhang ${ }^{1,3,+}$, Ke Cheng ${ }^{1,+}$, Hongyan $\mathrm{Li}^{4}$, Fawen Yin $^{3}$, Qiaoe Wang ${ }^{2}$, Li Cui ${ }^{1}$,

Shasha Yang ${ }^{1,+}$, Jinggang Nie ${ }^{1}$, Dayong Zhou ${ }^{3, *}$ and Beiwei Zhu ${ }^{3}$

1 School of Light Industry and Chemical Engineering, Dalian Polytechnic University, Dalian, 116034, China

2 Key Laboratory of Cosmetic, China National Light Industry, Beijing Technology and Business University, Beijing, 100048, China

3 National Engineering Research Center of Seafood, Dalian Polytechnic University, Dalian, 116034, China

4 Pharmaceutical College, Liaoning University of Traditional Chinese Medicine, Dalian, 116600,

China

+ These authors contributed equally to this work and should be considered co-first authors.

*Corresponding author:

Tel: +86 41186323453, Fax: +86 41186323262, E-mail address: zdyzf1@163.com (Dayong Zhou) 


\section{Table of Contents}

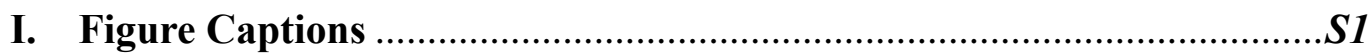

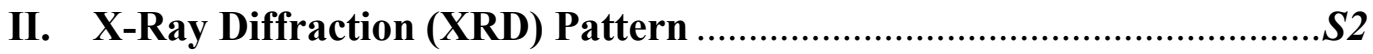

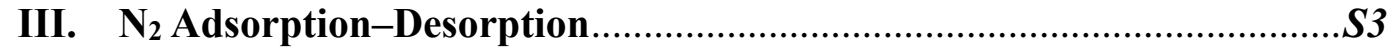

IV. Scanning Electron Microscopy (SEM) and Transmission Electron

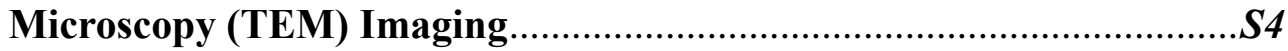

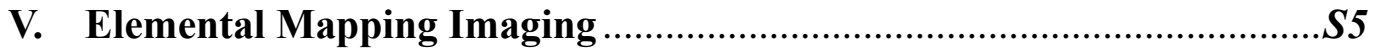

VI. Influences of Interesterification Parameters.......................................S6 


\section{Figure Captions}

Figure S1. (A) Small-angle and (B) wide-angle XRD patterns of the (a) SBA-15, (b) Zn-SBA-15, and (c) Ph-SO 3 H-Zn-SBA-15 samples.

Figure S2. (A, B, and C) $\mathrm{N}_{2}$ adsorption-desorption isotherms and (a, b, and c) poresize distributions of SBA-15, Zn-SBA-15, and Ph-SO ${ }_{3} \mathrm{H}-\mathrm{Zn}-\mathrm{SBA}-15$ samples.

Figure S3. SEM and TEM images of (A and a) SBA-15, (B and b) Zn-doped SBA-15 (Zn-SBA-15), and (C and c) sulfonated Zn-SBA-15 (Ph-SO $\left.{ }_{3} \mathrm{H}-\mathrm{Zn}-\mathrm{SBA}-15\right)$ samples.

Figure S4. Elemental mappings of the $\mathrm{Ph}-\mathrm{SO}_{3} \mathrm{H}-\mathrm{Zn}-\mathrm{SBA}-15$ sample.

Figure S5. Influences of interesterification parameters on production of structured phospholipids (SPLs) containing short-chain fatty acids (SCFAs) over the $\mathrm{Ph}_{-} \mathrm{SO}_{3} \mathrm{H}-$ Zn-SBA-15 catalyst: (A) Soybean lecithin (SL)/ethyl propionate (or methyl butyrate): 1:8, $50{ }^{\circ} \mathrm{C}, 6 \mathrm{~h}$; (B) Catalyst: $5.0 \mathrm{wt} . \%, 50{ }^{\circ} \mathrm{C}, 6 \mathrm{~h}$; (C) SL/ethyl propionate (or methyl butyrate): $1: 8$, catalyst: $5.0 \mathrm{wt} . \%, 50{ }^{\circ} \mathrm{C}$; (D) SL/ethyl propionate (or methyl butyrate): $1: 8$, catalyst: $5.0 \mathrm{wt} . \%, 6 \mathrm{~h}$. 


\section{X-Ray Diffraction (XRD) Pattern}
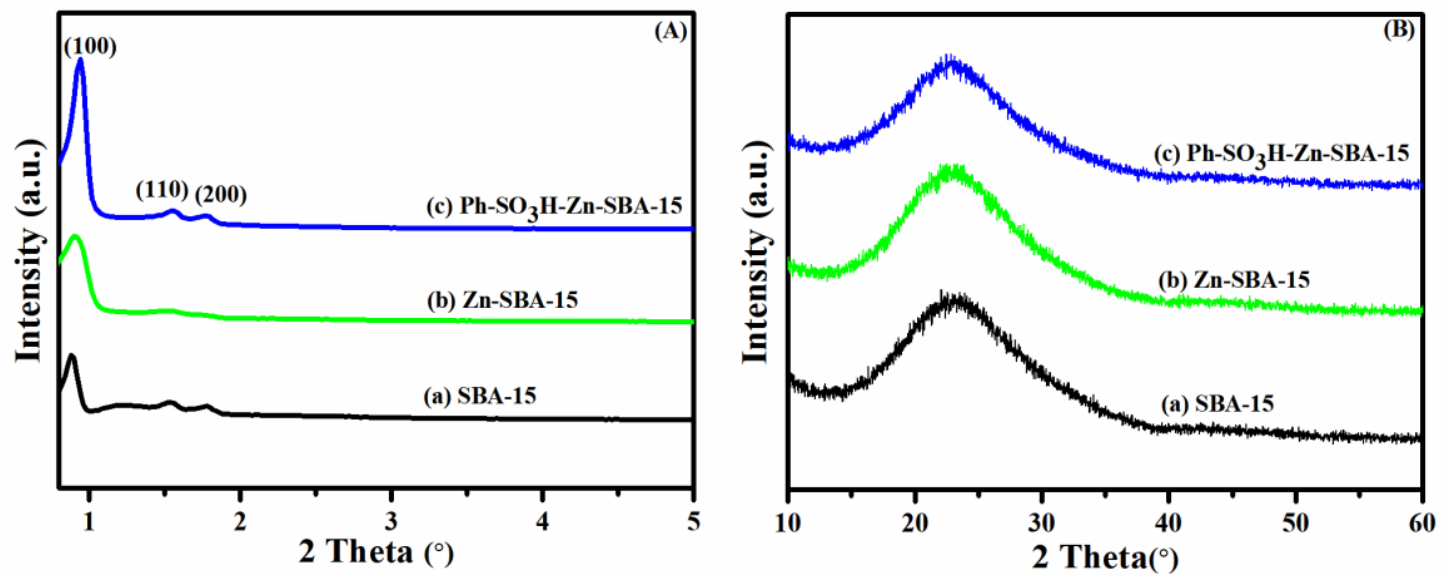

Figure S1. (A) Small-angle and (B) wide-angle XRD patterns of the (a) SBA-15, (b)

Zn-SBA-15, and (c) Ph-SO ${ }_{3} \mathrm{H}-\mathrm{Zn}-\mathrm{SBA}-15$ samples. 


\section{III. $\mathbf{N}_{2}$ Adsorption-Desorption}
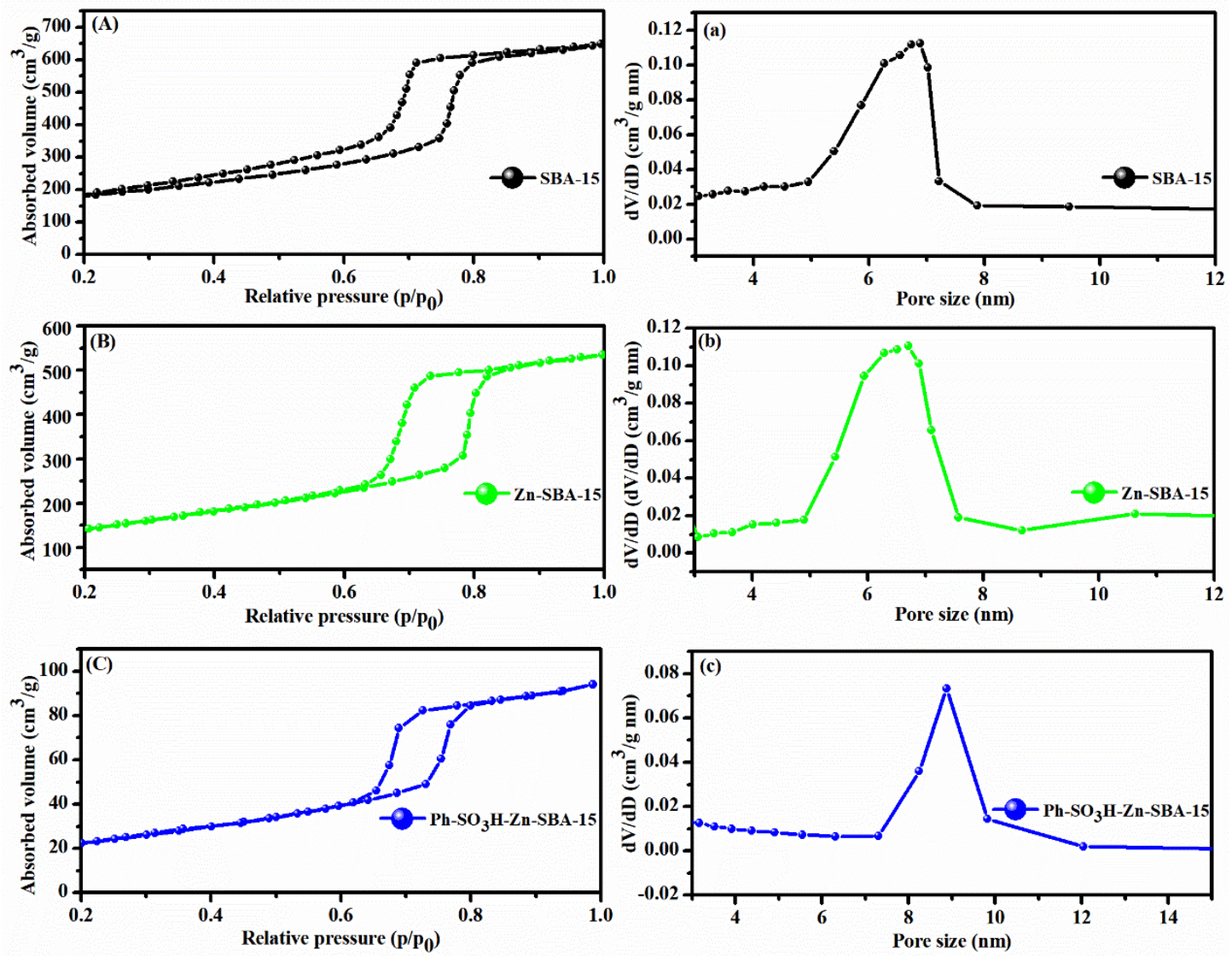

Figure S2. (A, B, and C) $\mathrm{N}_{2}$ adsorption-desorption isotherms and (a, b, and c) poresize distributions of SBA-15, Zn-SBA-15, and Ph-SO 3 H-Zn-SBA-15 samples. 


\section{Scanning Electron Microscopy (SEM) and Transmission Electron Microscopy (TEM) Imaging}

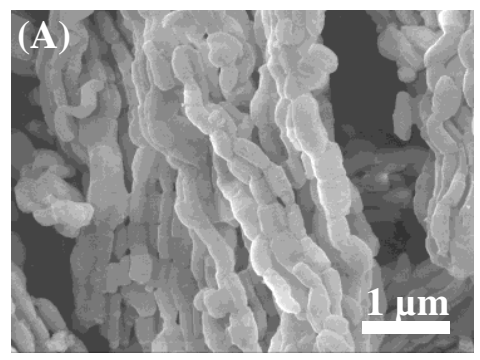

(a)
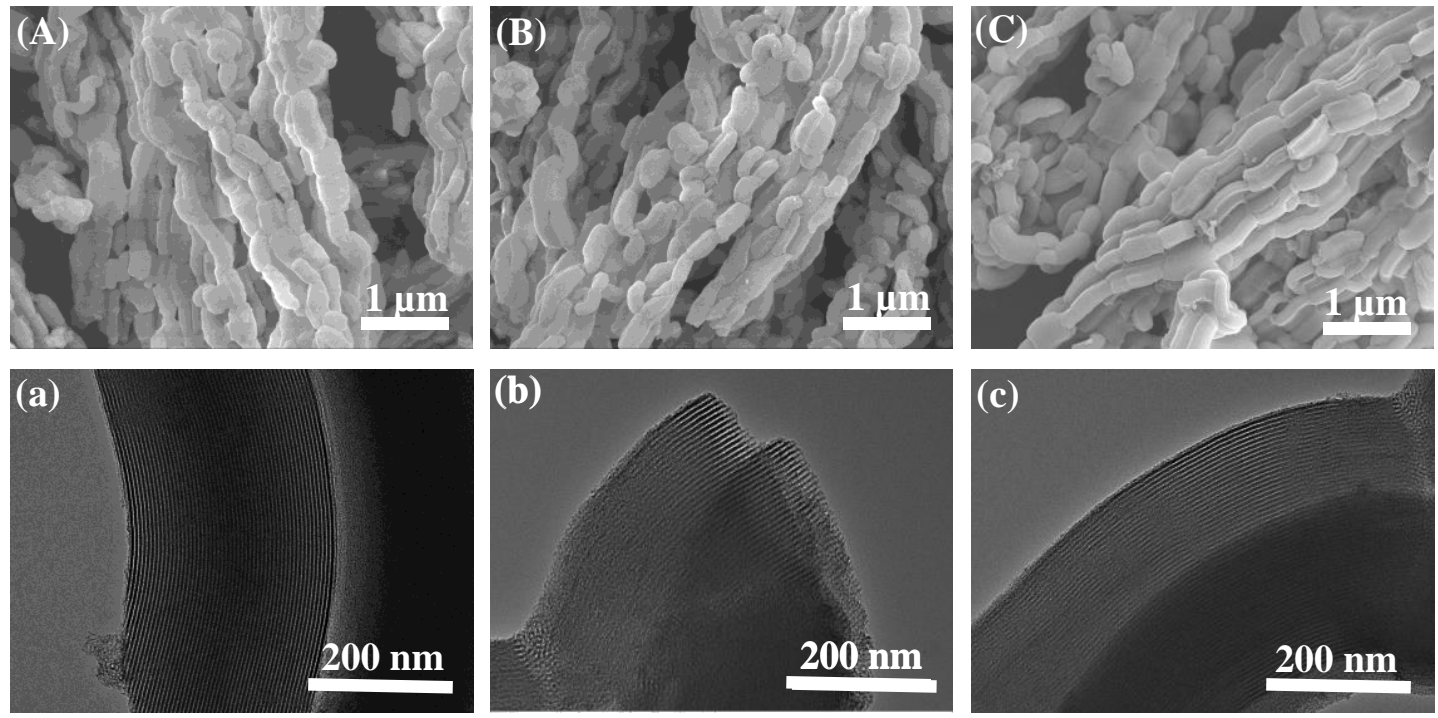

Figure S3. SEM and TEM images of (A and a) SBA-15, (B and b) Zn-doped SBA-15

(Zn-SBA-15), and (C and c) sulfonated Zn-SBA-15 (Ph-SO $\left.{ }_{3} \mathrm{H}-\mathrm{Zn}-\mathrm{SBA}-15\right)$ samples. 


\section{Elemental Mapping Imaging}
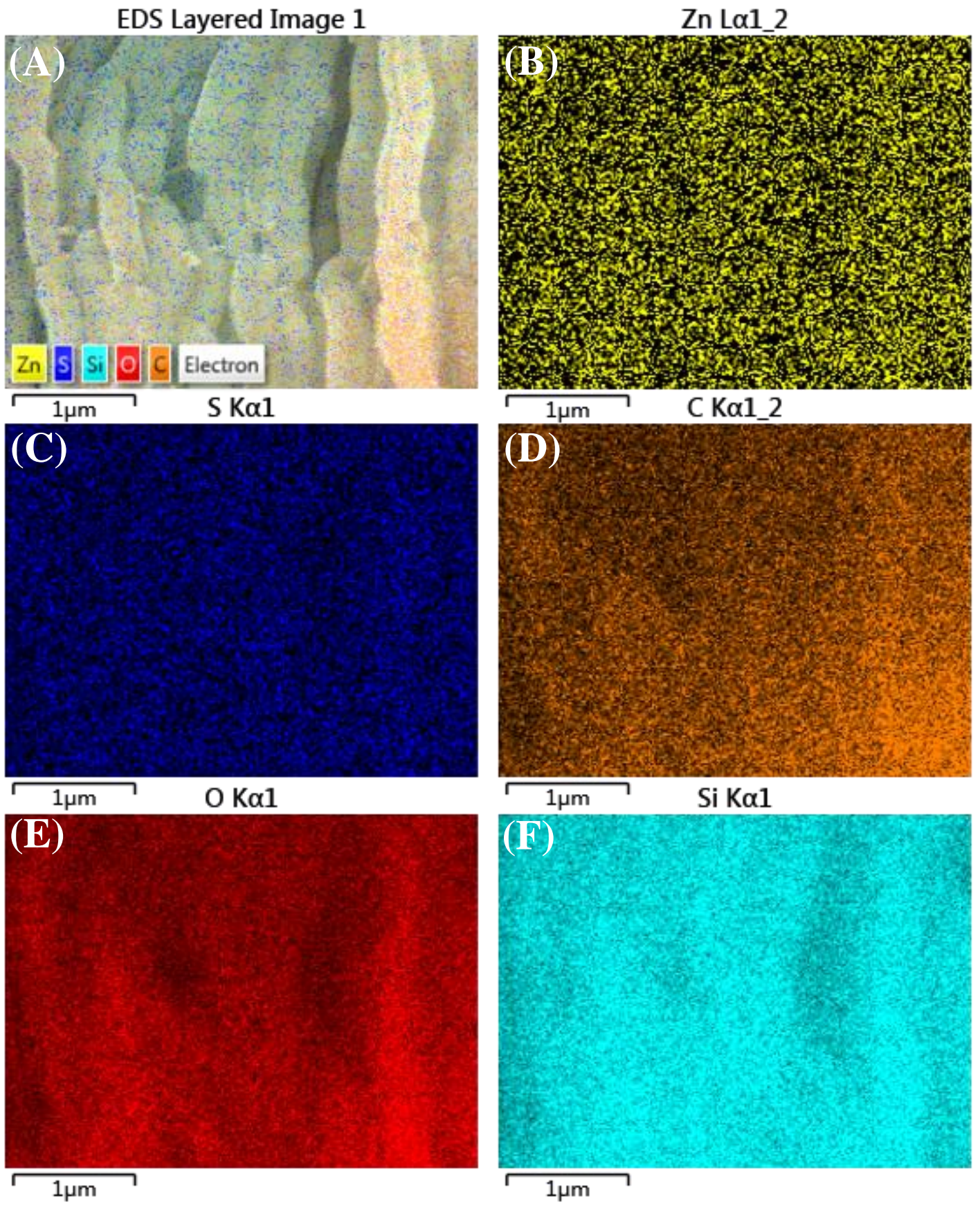

Figure S4. Elemental mappings of the $\mathrm{Ph}-\mathrm{SO}_{3} \mathrm{H}-\mathrm{Zn}-\mathrm{SBA}-15$ sample. 


\section{Influences of Interesterification Parameters}
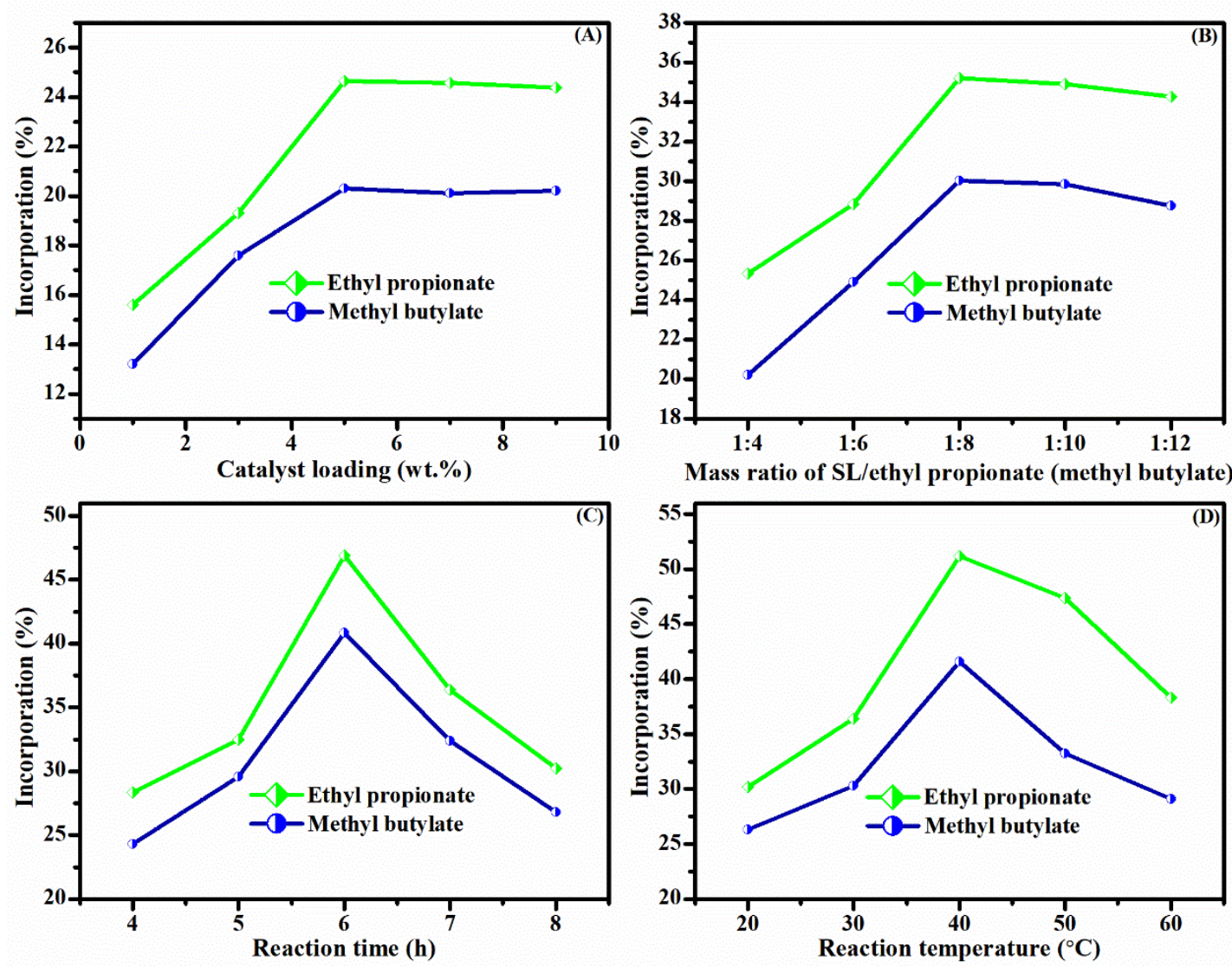

Figure S5. Influences of interesterification parameters on production of structured phospholipids (SPLs) containing short-chain fatty acids (SCFAs) over the $\mathrm{Ph}_{-} \mathrm{SO}_{3} \mathrm{H}-$ Zn-SBA-15 catalyst: (A) Soybean lecithin (SL)/ethyl propionate (or methyl butyrate): 1:8, $50{ }^{\circ} \mathrm{C}, 6 \mathrm{~h}$; (B) Catalyst: 5.0 wt. $\%, 50{ }^{\circ} \mathrm{C}, 6 \mathrm{~h}$; (C) SL/ethyl propionate (or methyl butyrate): $1: 8$, catalyst: $5.0 \mathrm{wt} . \%, 50{ }^{\circ} \mathrm{C}$; (D) SL/ethyl propionate (or methyl butyrate): 1:8, catalyst: 5.0 wt. $\%, 6$ h. 